\title{
The Engineering-science Intellectual Property (ESIP) Project: A Novel Method for Promoting Innovation
}

\author{
2018
}

\author{
Hamid R. Piroozi, Justin L. Hess, Charles Feldhaus \\ Indiana University-Purdue University of Indianapolis
}

This is the author's manuscript of the article published in final edited form as:

Piroozi, H.R., Hess, J. L., \& Feldhaus, C. (2018). The Engineering-science Intellectual Property (ESIP) Project: A Novel Method for Promoting Innovation. Presented at the 2018 ASEE Annual Conference \& Exposition. Retrieved from https://peer.asee.org/the-engineering-science-intellectual-property-esip-project-a-novel-method-for-promotinginnovation 


\title{
The Engineering-Science Intellectual Property (ESIP) Project: A Novel Method for Promoting Innovation
}

\begin{abstract}
In the idea economy, intellectual property (IP) is valued higher than other assets such as factories and equipment. Affirmation of this valuation is often observed when a company's IP advances or declines which causes a seismic shift in its stock price. IP law, however, is complicated and is evolving. As a result, new engineering and science graduates take many years, if ever, before they are familiar with the process of securing IP. Lack of such familiarity often results in IP being an after-thought in design processes. While others have attempted to discuss IP as part of a larger entrepreneurship setting in the form of a brief introduction of various IP vehicles, a solid understanding of what is protectable requires more than familiarity with IP concepts.

This paper describes the development and underlying theory of a novel educational program titled Engineering-Science Intellectual Property Project (ESIP-Project). This project includes three degree-counted elective courses that together create an IP concentration in an engineering BS curriculum. The intent of the project is to generate within students a deep understanding of IP requirements for creating novel, nonobvious, and non-infringing designs. In addition, the ESIPProject is designed to teach IP concepts as they relate to engineering design, as well as critical thinking skills and innovation. More specifically, students will be prepared to engage in prior art review, identify what is needed to obtain enforceable designs, and apply strategies to avoid infringement of existing patents. At the culmination of ESIP-Project, students will be prepared to pass the patent bar examination and become certified to practice patent law before the U.S. Patent and Trademark Office. Hence, graduates of the ESIP-Project will have new career options including choices for becoming patent engineers and patent agents, in addition to traditional technical career choices.

This paper includes an overview of the three-course sequence, as well as evaluation results of the implementation of the first course. A survey was designed by the investigators and implemented pre and post course. The survey included three constructs: Knowledge of IP Concepts, Innovative Product Design, and Careers in Patent Law. Following reliability testing procedures, student responses to these constructs were compared before and after course implementation. Despite the small sample size (15 students), comparative analyses suggested students experienced strong, positive gains in each construct. These positive changes in student responses from participation in just one of three IP courses is encouraging to our team. We hope that the ESIP-Project model, and our evaluation of the model as we scale it up, will provide a pathway for other educators to follow, particularly those who are interested in promoting entrepreneurship and innovation among their students.
\end{abstract}

Keywords: Intellectual Property; Patent Engineering; Innovation 


\section{A. Introduction}

That's why we love science. It's is more than a school subject, or the periodic table, or the properties of waves. It is an approach to the world, a critical way to understand and explore and engage with the world, and then have the capacity to change that world...

President Barack Obama, March 23, 2015 [1]

The Founders of the United States' democratic system of government realized the importance of innovation for the newly formed Republic. In Article I of the Constitution they bestowed upon the Congress powers it deems necessary, "To promote the progress of science and useful arts, by securing for limited times to authors and inventors the exclusive right to their respective writings and discoveries" [2]. Today we see a rich and complicated legal landscape that has evolved for the past 250 years within the US. The first patent was issued to Samuel Hopkins in 1790 and signed by George Washington [3] and now there are almost 10 million U.S. patents, representing an exponential rise in the last several decades. While the history of patent law within the US dates to the country's founding, patent law itself predates US' formation by centuries. The first generally recognized act goes back to 1474 in Venice [4], which included similar parameters as any modern patent act (i.e., exclusivity, term, scope of innovation, scope of infringement, and to whom these rights can attach). It is with this backdrop that today's patent practitioners find themselves. In Bilksi v. Kappos [5], a recent case related to patentable subject matter, the Court affirmed the historical evolution of technology from the industrial age to the information age. It is this evolution that has also necessitated changes in the US jurisprudence.

Acknowledging this rich and ever-evolving history, this project is guided by the theory that there is not only a need for those who innovate to understand fundamental IP concepts, but also to understand its historical developments and contemporary guiding parameters. Further, we anticipate that students' innovative potential will be greatly bolstered if they utilize IP concepts as a guidepost when designing with the goal of creativity and novelty. Lacking IP knowledge, there is a misalignment between what engineers and scientists create in their respective laboratories and what their counterpart patent practitioners expect to receive in a patent application.

In addition to bolstering students' creative potential, infusing IP into undergraduate engineering curriculum will save time in two ways. First, students learn how to begin a design project based on what is already known in an area, rather than recreate what is already known. Without that knowledge, months of engineering effort can be spent on developing a widget that already exists. That knowledge is not based on what is known to exist in the market place - after all it commonly known that only $10 \%$ of what is considered as prior art makes it to the marketplace but rather based on an understanding of the existing art. Second, when engineers innovate in the proverbial vacuum, they often create widgets that directly infringe others' intellectual property (IP). As one example, a recent case of Apple v. Samsung [6] that has traversed up and down the judicial ladder from the U.S. District Court for the Northern District of California to the Court of Appeals for the Federal Circuit to the Supreme Court of the US and back down has captured the nation's interest since 2011 when Apple sued Samsung. On August 24, 2012, the first jury reached a verdict that numerous Samsung smartphones infringed and diluted Apple's patents and trade dresses in various combinations and awarded over $\$ 1$ billion in damages. This ongoing saga has undoubtedly cost both companies valuable resources, represented by over seven years 
of litigation. A reverse set of litigations are also ongoing based on Samsung's suit against Apple, reaching outside of the US boarders. If only Samsung's and Apple's engineers had designed their products with IP concepts at the fore, rather than in a "traditional" engineering design process, these allegedly and already juror-decided infringing products would likely not have infringed.

This paper introduces a roadmap for a new engineering and science educational programming that helps engineering and science students internalize design practices grounded in IP concepts. Specifically, students are expected to utilize the rich body of knowledge in patent databases to innovate protectable designs. We hypothesize that this will boost students' creativity skills, as well as their development of a comprehensive understanding of the design process. In addition, design outcomes will, more likely than not, not infringe others' intellectual property. This new roadmap for infusing IP concepts into engineering students' design thinking is defined by a three-course sequence titled the Engineering Science Intellectual Property project (the ESIPProject). In essence, the ESIP-Project teaches students how to expediently transform an innovative idea into a protectible invention that will likely not infringe IP of others.

\section{B. Literature Review}

In a 1996 ASEE article, Callahan, Givens, and Montefusco [7] recognized an unmet need in engineering education, stating, "While many engineering curriculums provide the foundations for such endeavors [i.e., designing a new product or developing a new process], one area of instruction that is lacking is in the arena of protection of ideas" (p. 1). While little in the way of this paper's authors' pedagogical approach was discussed, in that paper the authors further suggested:

Students need to know what the future holds for them. The most valuable item that they have to offer an employer or a customer is their knowledge. Whether they ever file for a copyright or a patent, they must understand the consequences of being an intellectual property provider in an ever changing global market place. [7, p. 4]

While Callahan and colleagues' article was published more than 20 years ago, today there remain few precedents for integrating IP concepts into engineering and science curriculum. As one exception, in an article titled, "Using Intellectual Property to Enhance Engineering Education," [8] the authors discuss the importance of IP education in engineering. In this article, the authors describe concepts such as the right to own IP, infringement, copyrights, trademarks, and patents for engineers. In particular, the article discusses the alignment between IP and the goals of ABET Engineering Criteria 2000, which include "an ability to design," "a knowledge of contemporary issues," and "an understanding of professional and ethical responsibility." The authors posited, "IP encompasses design and identifies the latest contemporary issues associated with engineering. More importantly, it is an engineer's professional and ethical responsibility to research claims prior to publication or use" (p. 1). While the authors recognized the importance of IP in engineering education, the scope of their pedagogical approach was limited. For example, the project scope was restricted to the following: "the engineering students have been introduced to an overview of IP and have been required to perform IP searches within their assignments" (p. 11). While, prior art searching is an important component of the ESIP-Project described herein, it is but a small fraction of the overall project. 
In a more recent article, Vairis and Petousis [9] discussed courses which "are described in terms of goals and procedures which teach students IP rights to prepare them to benefit the maximum in today's knowledge-based economy" (p. 1). According to a 2002 survey, to which the authors refer, "the vast majority of $70 \%$ [of approximately 2000 respondents] felt that IP is relevant to their future career and a bigger share $80 \%$ that it was important to know about IP" (p. 3). The authors argued, "Engineers and scientists need to familiarize themselves with the basic concepts of IP, so that when they engage in any creative undertaking, they will be aware of the interaction between their intellectual work and the IP system" (p. 3). In other words, at the end of their academic career (i.e., upon graduation), engineers and scientists need to possess a general awareness of what IP is and how to utilize it beneficially while understanding the hazards of infringing other people's IP assets.

These past efforts describe strategies to familiarize students with IP concepts. In each program, they seek to teach a general concept of IP by providing a generic approach so that the students recognize when they may have reached an innovative idea by happenstance (i.e., sensitize the students to when the proverbial light bulb lights up). What these studies do not include is a structured approach for teaching students how to make the transformation from an otherwise unpatentable innovation, because the subject matter of the innovation belongs to an unpatentable class of innovations or because the innovation is not novel or is considered as obvious, into an invention that is likely patentable as well as a methodology for evaluating students' attainment of IP knowledge. The ESIP-Project, described next, is an intentional pedagogical approach designed towards these ends. Evaluation of the intervention is a core component of its implementation. Course 1 evaluation findings are discussed in the subsequent sections.

\section{Engineering-Science Intellectual Property Project (ESIP-Project)}

The overarching goal of the ESIP-Project is to teach students how to begin and proceed with the design process by utilizing IP knowledge as a starting point and throughout the design phases. The key component is to begin the design process on the correct path and then adjust the path during the process as needed. In doing so, we hypothesize that students will learn how to produce higher quality designs, more innovative solutions, and designs that will likely not infringe existing IP. In addition, the students learn about the bundle of rights associated with a technology and how to divide the technology into what is best kept as tradesecret vs. patentable subject matter vs. other forms of IP (e.g., copyrights) to best take advantage of what the US and foreign laws afford them. Without this knowledge, students who later become engineers will likely design or innovate without concern for IP. The three-course sequence of the ESIP-Project represents two semesters during which all three courses are offered in the institution of the authors of this paper. The three courses include:

- Course 1: Innovative Product Design with Emphasis in Intellectual Property

- Course 2: Design for Patentability

- Course 3: Intellectual Property Rights for Engineers

Each course includes a technical design phase along with coverage of IP concepts. In the first course, design projects are carried out with an in-depth patent concept training relevant to preparing patent applications as well as basic to moderate coverage of other IP concepts including trademark, tradesecret and copyright. In the second course, more complex design 
projects are carried out with in-depth patent concept training designed to improve understanding of patent application examination as well as other more advanced patent preparation concepts. In the third course, similarly more complex design projects are carried out while introducing soft IP concepts such as IP valuation, IP transactions, and IP litigation. The design phase lasts about up to eight weeks in each course, during which time students begin grappling with IP concepts.

The lead author of this paper is the instructor in these classes and provides directions to the students related to transformation of each project from a first state that is far less likely to be protectible, to a second state which is more likely patentable. It is through this transformation that the students gain knowledge they can utilize as they advance to their next phases of education and professional careers. At the end of each design phase, in each course students prepare and file patent applications directed to their inventions. In Course 1, in certain situations, students file patent applications based on expedited examination with the hopes that by the end of the following semester, the United States Patent and Trademark Office (USPTO) will have provided examination feedback in the form of examination. The feedback will be in the form of office actions from the USPTO that will teach students practical knowledge as to how their efforts in searching, innovating, and preparing the application has paid off in the form of official examination by the USPTO.

The IP principals of interest include deep coverage of patent concepts, low to moderate coverage of copyright, trademark, and tradesecret concepts. In the Course 1, concepts of prior art searching and strategies associated with those searches are discussed. Thereafter, concepts associated with patentable subject matter, utility, enablement, written description requirement, novelty, non-obviousness, and claim drafting are discussed. For each of these concepts, an inverted funnel approach is used, as depicted in Figure 1.

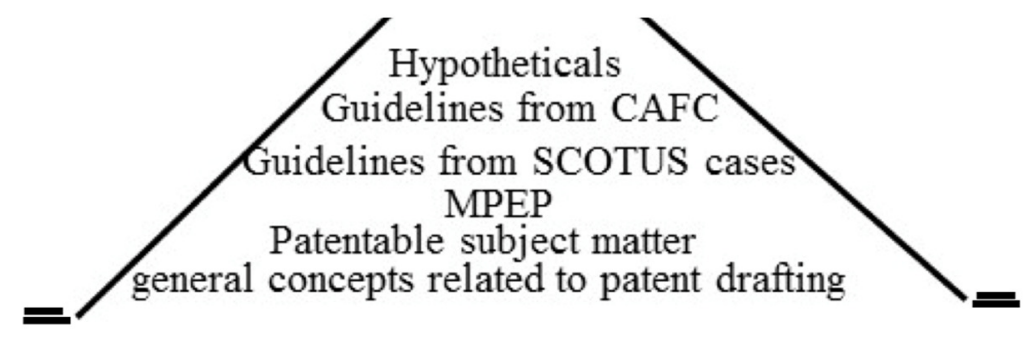

Figure 1. ESIP Approach

Initially, general concepts germane to patent drafting are introduced. For example, with respect to patentable subject matter, general historical information is initially discussed regarding how today's contemporary concepts are formed over the last 2 centuries. Such a historical perspective reinforces previously discussed IP concepts as well as those that are subsequently introduced. Thereafter, practical knowledge dealing with everyday patent drafting with respect to patentable subject matter are provided. These concepts are covered from the manual of patent examining procedures (MPEP). Next, recent guidelines provided by the USPTO in light of several Supreme Court (SCOTUS) cases as well as several Court of Appeals for the Federal Circuit (CAFC - a circuit that was specifically created to hear cases related to IP) cases are discussed. Thereafter, the students work through hypothetical situations or case studies to practice applying these IP concepts. The same process is repeated for the other concepts identified in Figure 1 to effectively guide the students as they carry out design projects while repeatedly reinforcing IP. 
As students engage in their design process, they are divided into groups based on interests in technology areas and engineering and technology majors. Groups collaborate on a design project that is either assigned to them or of their own conception. At the beginning of each course, students are divided into subgroups - about 30 students per class divided into 5-6 subgroups after identifying general areas of interests. Example projects from the Course 1 include inflatable earbuds for reducing external ambient noise, anti-skidding apparatus for automobiles, phone case for individuals with limited dexterity, a dustpan system for removing debris, and a cooler with improved thermal gradient.

Regardless of whether projects are assigned or self-conceptualized, the next step includes learning how to navigate issued patents or published patent applications of the project domain and identifying white spaces available in that area. Once the white space has been identified, the students are asked to apply the patent concepts discussed above (i.e., Figure 1) to implement an innovative design, as defined by a design that has not been previously disclosed but that meets a core need or functions in a novel and potentially marketable manner. The design can be an improvement over the existing art, or a wholly innovative approach to solving a problem. Given that the students may not have a full grasp of the IP concepts at this point, the instructor serves as a continual source of "soft scaffolding" by helping the students associate the IP concepts with their design activities. This is especially important, as different learners need varied levels and forms of support.

As a core part of the design phase, each group prepares a patent application. Importantly, for almost every design generated in the course, and given that these designs are out of physical sciences, no actual prototyping is necessary. Simply designing with pen and paper or on the computer is sufficient for filing a patent application. Furthermore, while a thorough theoretical understanding of IP concepts would help ensure a "successful" patent application, no such requirement is imposed by our patent system. Therefore, constructively reducing the design to practice by performing simple calculations, simulations, and rudimentary computer-aided design work followed by an enabling description of the design in the patent application is all that is necessary. However, this form of legitimate peripheral participation - as students are authentically engaging in the patenting act in proximity to an experienced patent professional [10] - is a critical pedagogical strategy to help realize the broader goal of the development of a holistic awareness of IP concepts.

One important aspect of patent drafting is claim drafting. Patent applications are divided into the written description (typically identified as specification), drawing (if needed), and claims. Claims are provided in the forms of independent as well as dependent claims in a funnel approach with the independent claims providing the broadest scope of protection (i.e., covering the most number of potentially infringing products or methods), and the dependent claims are progressively narrower. Patent applications are examined, and patents are enforced based on the claims and the scope of protection they provide. Claims are supported by the specification but are given their broadest reasonable interpretation in light of the specification.

During the design phase, students are asked to prepare claims, from simple to more complex concepts. Claims are divided into system-level claims, method claims, apparatus claims, kit claims, and composition of matter claims. Claim drafting becomes more complex with the 
advancement of courses. In Course 1, rudimentary infringement concepts are discussed to assist with claim drafting (i.e., how the claim should be drafted to cover as many infringing products or methods, who will be needed in a court). Later, in Courses 2 and 3, in-depth infringement concepts are discussed to assist with drafting claims based on at least one operable theory of infringement (i.e., single party direct infringement, multi-party direct infringement, or multiparty indirect infringement via inducement and/or contributory infringement). Students are expected to supply a short summary of the operable infringement theory for each independent claim of the patent application.

Once the design phase is complete, students file their patent applications with the USPTO to receive an official serial number. Only some or all applications in the first course are based on the accelerated examination (Track-I), where the USPTO promises to reach a finality within one year of the application filing date. Each student team is graded based on their prior art search, the quality of the design, integration of IP concepts within the design, as well as the quality of the application. Once the patent application portion of each course is completed, each course continues to provide further IP concepts.

Table 1. List of IP concepts Integrated throughout ESIP

\begin{tabular}{|c|c|c|c|}
\hline & Course 1 & Course 2 & Course 3 \\
\hline \multicolumn{4}{|l|}{ Claims } \\
\hline System-level & $\mathrm{X}$ & $\mathrm{X}$ & $\mathrm{X}$ \\
\hline Method & $\mathrm{X}$ & $\mathrm{X}$ & $\mathrm{X}$ \\
\hline Apparatus & $\mathrm{X}$ & $\mathrm{X}$ & $\mathrm{X}$ \\
\hline Kit & $\mathrm{X}$ & $\mathrm{X}$ & $\mathrm{X}$ \\
\hline Composition of Matter & $\mathrm{X}$ & $\mathrm{X}$ & $\mathrm{X}$ \\
\hline \multicolumn{4}{|l|}{ IP Concepts } \\
\hline Copyrights & $\mathrm{X}$ & & \\
\hline Trademarks & $\mathrm{X}$ & & \\
\hline Trade secrets & $\mathrm{X}$ & & \\
\hline IP Portfolio Design and Management & $\mathrm{X}$ & & $\mathrm{X}$ \\
\hline Infringement Analysis & $\mathrm{X}$ & & $\mathrm{X}$ \\
\hline IP Valuation & & & $\mathrm{X}$ \\
\hline Product Market Assessment & & & $\mathrm{X}$ \\
\hline IP Transactions & & & $\mathrm{X}$ \\
\hline Patentable Subject Matter & $\mathrm{X}$ & $\mathrm{X}$ & \\
\hline Novelty & $\mathrm{X}$ & $\mathrm{X}$ & \\
\hline Non-Obviousness & $\mathrm{X}$ & $\mathrm{X}$ & \\
\hline Patent Prosecution (Examination) & & $\mathrm{X}$ & \\
\hline Specific MPEP Concepts for the Patent Bar & & $\mathrm{X}$ & \\
\hline
\end{tabular}

In Courses 1 and 3, additional IP concepts include basic but practical IP knowledge such as copyrights, trademarks, tradesecrets, IP portfolio design and management, infringement analysis, claim charts, IP valuation, product market assessment, and IP transactions. For each of these areas, students learn basic concepts of how corporations manage their IP. These concepts can enhance each student's career by providing more than a passing familiarity with complex and 
often involved challenges to corporations. In the second course, the additional IP lessons include a deep dive into patent concepts.

In Course 2, material from the MPEP are presented with respect to prosecution (i.e., examination) of patent applications. These concepts are intended to teach students knowledge they will need to have to pass the patent bar examination. That exam can be taken in the summer following the completion of the second course. The pass rate of the patent bar exam has been historically low (between $43 \%$ to $47 \%$ over the past five years [11]). Gaining an in-depth understanding of the MPEP chapters increases the ability of students to pass the patent bar.

Responding to hypothetical office actions (one can navigate to the USPTO website and download recently mailed office actions for which there are no responses yet) are part Course 2 lessons and are also part of the evaluation. One aspect of office action responses is to learn how to think in a logical manner and to present arguments orderly. A significant challenge in generating an office action response is to determine what the underlying difficulty an examiner has with allowing the patent application to issuance. An effective response includes addressing those underlying points in a logical and orderly manner.

\section{Methods}

This evaluation study includes findings from the implementation of Course 1 implemented in the Fall of 2017. A pre-and-post survey, designed by Author 1 and reviewed by Authors 2 prior to use, was implemented before and after Course 1 activities. Institutional Review Board approval was acquired for all components of survey delivery. An evaluator, Author 2, external to the instructor (i.e., Author 1) administered the survey pre and post and conducted the analysis reported herein.

Fifteen (15) complete pre and post responses were collected to the ESIP survey, representing $100 \%$ of Course 1 participants. All students were enrolled in an engineering major (14 in Mechanical Engineering; 1 in Electrical Engineering). Most students were male $(\mathrm{n}=14)$ and only one student was female. Participant age ranged from 20 to $29(M=22.8, S D=2.68)$. Participants were primarily White or Caucasian $(\mathrm{n}=11)$ followed by Asian or Pacific Islander $(\mathrm{n}$ $=2)$ and Multi-Racial $(n=1)$. Note that one student declined to specify race. Only one student was not originally from the USA (Malaysia). Most students were non-transfers $(n=10)$ and 5 students were transfers to the university. 10 students were full-time and 5 were part-time. The average major GPA of participants was 3.10, $S D=0.33$ and the average overall GPA was 3.08, $S D=0.36$. Lastly, four students were Pell eligible.

Three survey constructs were designed to ascertain students' self-perceived mastery of three overarching course objectives: Knowledge of IP Concepts, Innovative Product Design, and Careers in Patent Law. Knowledge of IP Concepts included 11 items that ascertained students self-reported understanding of basic concepts, such as novelty and non-obviousness, registering copyrights, and misappropriation. Innovative Product Design included 12 items that focused on students' self-reported knowledge regarding how to infuse IP into their design process. Lastly, Careers in Patent Law included three items pertaining to students' general awareness of patentrelated careers. 
Students responded to survey items given the prompt, "Please identify your level of knowledge regarding the following concepts." Students responded on a five-point Likert-type scale where 1 = None, 2 = Minimum, 3 = Moderate, $4=$ High, $5=$ Expert. As the surveys were newly constructed by the research team, reliability testing preceded comparative analyses. These reliability testing procedures involved computing the internal consistency reliability through Cronbach's alpha. Factor analytic procedures could not be utilized due to the small sample size.

In addition to the Likert-type responses, students responded to three open-ended questions: (1) Describe your knowledge of what each different type of patent protects; (2) Describe the sections of a patent application and the procedural processes regarding how one files a patent application; and (3) Describe the steps you take when designing a product. Analysis of these open-ended responses is not reported herein.

\section{E. Results}

\section{E.1. Overview of Student Projects}

During the Fall of 2017, 15 students enrolled in Course 1 created designs in a variety of different fields. Examples include an earbud design that blocks outside noise when worn by a user (e.g., when in an airplane blocking engine noise), apparatus design to stop a vehicle uncontrollably sliding on an icy or oily surface (e.g., when there is an ice storm or a rain storm after a long time since last precipitation), cooler design that allows placement of containers therein with ergonomic placement of ice about thereon, and ergonomic design of a socket for cellular phones for individuals with limited dexterity. One of the applications in the Fall semester was filed based on Track I (fast track) at the USPTO which has produced an office action in the Spring 2018 semester. At the time of the writing, this office action is being addressed by the corresponding student group.

\section{E.2. Changes in ESIP Concepts}

Descriptive statistics were computed for each survey item. Next, the items were checked for internal consistency reliability by computing Cronbach's alpha. The data evidenced acceptable $(\alpha>.70)$ to excellent reliability $(\alpha>$.80) [12] for nearly every construct, with the exception of pre-course responses to the Careers in Patent Law construct, which was minimally acceptable $(\alpha$ $=.69$ ). Given its proximity to the proposed threshold of .70 for acceptability, and the excellent internal consistency reliability evidenced from post-course responses $(\alpha=.83)$, the construct was retained as originally designed.

Next, the data were aggregated into single scores and standardized so that each construct was on the same Likert-scale as individual item responses. A review of the pre and post course item mean responses revealed strong gains on each construct. Specifically, student responses increased on the Knowledge of IP Concepts construct from pre $(M=1.73, S D=.63)$ to post $(M=$ $3.78, S D=.50)$ by 2.05 points; Innovative Product Design from pre $(M=1.53, S D=.56)$ to post $(M=3.68, S D=.50)$ by 2.15 points; and Careers in Patent Law from pre $(M=1.84, S D=.58)$ to post $(M=3.58, S D=.85)$ by 1.73 points. Table 2 provides an overview of this data. 
Table 2: Descriptive Statistics: Pre/Post ESIP Survey

\begin{tabular}{|c|c|c|c|c|c|}
\hline \multirow{2}{*}{ Construct and Items } & \multicolumn{2}{|c|}{ Pre } & \multicolumn{2}{|c|}{ Post } & \multirow[b]{2}{*}{$\Delta$} \\
\hline & $M$ & $S D$ & $M$ & $S D$ & \\
\hline Knowledge of IP Concepts $\left(\alpha_{P r e}=.92 ; \alpha_{\text {Post }}=.86\right)$ & 1.73 & $\mathbf{0 . 6 3}$ & 3.78 & $\mathbf{0 . 5 0}$ & 2.05 \\
\hline basic patent concepts such as novelty and non-obviousness & 2.27 & 0.80 & 4.00 & 0.65 & 1.73 \\
\hline $\begin{array}{l}\text { basic concepts of different types of patents, e.g., design, utility, and } \\
\text { plant }\end{array}$ & 1.67 & 0.98 & 3.60 & 0.74 & 1.93 \\
\hline basic trademark concepts such as likelihood of confusion & 1.80 & 0.68 & 3.80 & 0.56 & 2.00 \\
\hline $\begin{array}{l}\text { basic copyright concepts, e.g. defenses to infringement such as fair } \\
\text { use }\end{array}$ & 2.00 & 0.85 & 4.00 & 0.65 & 2.00 \\
\hline procedural requirements for obtaining a patent for your idea & 2.07 & 1.10 & 4.20 & 0.56 & 2.13 \\
\hline substantive requirements for obtaining a patent for your idea & 1.80 & 0.86 & 4.07 & 0.70 & 2.27 \\
\hline basic trade secret concepts such as misappropriation & 1.53 & 0.83 & 3.87 & 0.64 & 2.33 \\
\hline $\begin{array}{l}\text { procedural requirements for obtaining a trademark for a } \\
\text { product/company }\end{array}$ & 1.33 & 0.62 & 3.40 & 0.91 & 2.07 \\
\hline $\begin{array}{l}\text { substantive requirements for obtaining a trademark for a } \\
\text { product/company }\end{array}$ & 1.33 & 0.62 & 3.53 & 0.99 & 2.20 \\
\hline procedural requirements for registering copyrights & 1.67 & 0.90 & 3.60 & 0.91 & 1.93 \\
\hline substantive requirements for registering copyrights & 1.53 & 0.83 & 3.53 & 0.92 & 2.00 \\
\hline Innovative Product Design $\left(\alpha_{\text {Pre }}=.91 ; \alpha_{\text {Post }}=.90\right)$ & $\mathbf{1 . 5 3}$ & 0.56 & 3.68 & 0.50 & 2.15 \\
\hline $\begin{array}{l}\text { how to use IP concepts such as patentable subject matter when } \\
\text { beginning to design a widget }\end{array}$ & 1.27 & 0.59 & 3.87 & 0.64 & 2.60 \\
\hline $\begin{array}{l}\text { how to transform an idea from one that does not belong to a class of } \\
\text { patentable subject matter into one that does }\end{array}$ & 1.47 & 0.74 & 3.80 & 0.56 & 2.33 \\
\hline $\begin{array}{l}\text { prosecution of a patent (patent examination procedures) with the } \\
\text { United States Patent and Trademark Office (USPTO) for } \\
\text { obtaining a patent for your idea }\end{array}$ & 1.33 & 0.49 & 3.60 & 0.74 & 2.27 \\
\hline $\begin{array}{l}\text { how to build a portfolio of IP for obtaining a stronger IP position for } \\
\text { your idea }\end{array}$ & 1.27 & 0.59 & 3.33 & 0.72 & 2.07 \\
\hline $\begin{array}{l}\text { how to design claims that are not easily circumvented (worked } \\
\text { around) }\end{array}$ & 1.67 & 0.90 & 3.60 & 0.83 & 1.93 \\
\hline $\begin{array}{l}\text { how to design claims consistent with classical and modern } \\
\text { infringement theories }\end{array}$ & 1.47 & 0.74 & 3.60 & 0.74 & 2.13 \\
\hline designing a widget that does not infringe on existing IP rights & 1.33 & 0.62 & 3.53 & 0.74 & 2.20 \\
\hline how an infringement law suit proceeds in a patent context & 1.27 & 0.59 & 3.67 & 0.72 & 2.40 \\
\hline $\begin{array}{l}\text { how an engineer/scientist can assist in an infringement law suit in a } \\
\text { patent context }\end{array}$ & 2.07 & 0.70 & 3.80 & 0.68 & 1.73 \\
\hline $\begin{array}{l}\text { the concepts relative to patent law as to utility, enablement, written } \\
\text { description requirements, novelty, non-obviousness as it relates to } \\
\text { claim drafting }\end{array}$ & 1.53 & 0.92 & 3.93 & 0.59 & 2.40 \\
\hline $\begin{array}{l}\text { how to effectively perform a prior art search for existing patent } \\
\text { references }\end{array}$ & 2.07 & 1.28 & 3.93 & 0.80 & 1.87 \\
\hline $\begin{array}{l}\text { how to effectively perform a prior art search for existing trademark } \\
\text { references }\end{array}$ & 1.67 & 0.98 & 3.53 & 0.83 & 1.87 \\
\hline Careers in Patent Law $\left(\alpha_{\text {Pre }}=.69 ; \alpha_{\text {Post }}=.83\right)$ & 1.84 & 0.58 & 3.58 & 0.85 & 1.73 \\
\hline the requirements for becoming a registered patent practitioner & 1.47 & 0.64 & 3.60 & 1.12 & 2.13 \\
\hline career choices involving patents in a company & 2.07 & 0.96 & 3.67 & 0.98 & 1.60 \\
\hline careers involving patents on your own (be your own boss) & 2.00 & 0.53 & 3.47 & 0.83 & 1.47 \\
\hline
\end{tabular}


The difference scores (i.e., the difference between post-course and pre-course survey responses) were checked for normality by analyzing each constructs' histogram and computing the ShapiroWilks coefficients. Despite the small sample size $(\mathrm{n}=15)$, the difference scores of the constructs Knowledge of IP Concepts $(W=.94, p=.39)$, Innovative Product Design $(W=.99, p=.99)$, and Careers in Patent Law $(W=.90, p=.11)$ were each approximately normal [13].

A series of paired samples t-tests were conducted to evaluate the impact of the course on student responses to each ESIP survey construct. This analysis indicated that students' responses significantly increased on the Knowledge of IP Concepts construct $(t=10.98, p<.001$, twotailed) with a large effect size $\left(\eta^{2}=.90\right)$; Innovative Product Design construct $(t=11.02, p<$ .001 , two-tailed) with a large effect size $\left(\eta^{2}=.90\right)$; and the Careers in Patent Law construct $(t=$ $6.11 ; p<.001$, two-tailed) with a large effect size $\left(\eta^{2}=.73\right)$. Note that Cohen's [14] for the magnitude of effect sizes was used (i.e., $\eta^{2}>.14=$ large effect).

Table 3. Paired t-test results for survey constructs

\begin{tabular}{lccccccc}
\hline Construct & $\begin{array}{c}\text { Mean } \\
\text { Delta }\end{array}$ & $\begin{array}{c}\text { Std. } \\
\text { Deviation }\end{array}$ & $\begin{array}{c}\text { Std. Error } \\
\text { Mean }\end{array}$ & $\begin{array}{c}\mathbf{9 5 \%} \\
\text { CI } \\
\text { Lower }\end{array}$ & $\begin{array}{c}\mathbf{9 5 \%} \\
\text { Up }\end{array}$ & t-stat & $\boldsymbol{\eta}^{2}$ \\
\hline $\begin{array}{l}\text { Knowledge of IP } \\
\quad \text { Concepts }\end{array}$ & 2.05 & .72 & .187 & 1.65 & 2.46 & $10.98^{* * * *}$ & .90 \\
$\begin{array}{c}\text { Innovative Product } \\
\quad \begin{array}{c}\text { Design } \\
\text { Careers in Patent Law }\end{array}\end{array}$ & 2.15 & .76 & .195 & 1.73 & 2.57 & $11.02^{* * * *}$ & .90 \\
\hline
\end{tabular}

*** $p<.001$ (two-tailed); $\eta^{2}=t^{2} /\left(\mathrm{t}^{2}+d f\right) ; d f=\mathrm{N}-1=14$.

\section{E.3. Post-Course Responses}

A post-course survey was designed, building on Scaffolding and Interactivity scales described by Hess et al. [15]. Here, scaffolding is defined as one's "perceived effectiveness of course components that involve structured thinking." Scaffolding varies in terms of "hard" scaffolds, or rigid and universal supports that are put in place for students to leverage as they work through materials, and "soft" scaffolds, or the student-specific feedback that an instruct provides to help students advance from lower to higher levels of content or skill mastery [16]. The Scaffolding scale primarily encapsulates aspects of the former.

Interactivity is defined as "perceived effectiveness of course components that involve interactions." The Interactivity scale included both aspects of soft-scaffolding that were directly related to instructor-interactivity, as well as soft-scaffolding in the form of peer support that may have naturally arose as students collaborated. In addition to these two scales, a general satisfaction survey was developed to provide formative feedback for subsequent iterations.

The post-course data were aggregated into a single score and standardized so that each construct was on the same Likert scale as individual item responses. Through this process, one item that was originally on the Scaffolding scale was moved to the Interactivity construct: "When the material was challenging, I was able to find the support or feedback that I needed from the 
instructor." Upon closer inspection, this item more closely represents "soft" scaffolding as opposed to the other scaffolding items that more closely resemble "hard" scaffolding. Further, it included common features of the interactivity items, specifically, involving human-feedback either from peers or the instructor.

Table 4 provides an overview of individual item responses and scale responses. All responses were positive. In order of magnitude, students responded favorably to the Course Satisfaction scale $(M=4.56, S D=.40)$, Scaffolding $(M=4.32, S D=.59)$, and Interactivity $(M=4.30, S D=$ .53). While this high-level inspection is encouraging, a closer inspection reveals that the lowest response was to the individual question, "The feedback I received from my classmates helped me learn IP concepts," $(M=3.87, S D=.83)$. This may suggest that one area of improvement for subsequent offerings involves promoting peer collaboration and support.

Table 4: Post-Course Questionnaire Results

\begin{tabular}{|c|c|c|}
\hline Construct / Item & $M$ & $S D$ \\
\hline Scaffolding $(\alpha=.72)$ & 4.32 & 0.59 \\
\hline $\begin{array}{l}\text { When I had questions about the course, I was able to find the support or } \\
\text { feedback that I needed from the instructor. }\end{array}$ & 4.73 & 0.46 \\
\hline The structure and presentation of the materials helped me learn the material. & 4.20 & 0.77 \\
\hline $\begin{array}{l}\text { When I had questions about course content, I was able to find the resources I } \\
\text { needed on Canvas. }\end{array}$ & 4.20 & 0.86 \\
\hline $\begin{array}{l}\text { When the material was challenging, I was able to find the resources I needed } \\
\text { on Canvas. }\end{array}$ & 4.13 & 0.99 \\
\hline Interactivity $(\alpha=.81)$ & 4.30 & 0.53 \\
\hline $\begin{array}{l}\text { When the material was challenging, I was able to find the support or } \\
\text { feedback that I needed from the instructor. }\end{array}$ & 4.67 & 0.62 \\
\hline The discussion led by the instructors facilitated my learning of IP concepts. & 4.47 & 0.92 \\
\hline My opportunities to participate in discussions were sufficient. & 4.47 & 0.74 \\
\hline The interactions I had with my peers supported my learning. & 4.20 & 0.56 \\
\hline Hearing the opinions of others helped me learn the material. & 4.13 & 0.74 \\
\hline The feedback I received from my classmates helped me learn IP concepts. & 3.87 & 0.83 \\
\hline General Course Satisfaction $(\alpha=.83)$ & 4.56 & 0.40 \\
\hline Instructor was knowledgeable. & 4.93 & 0.26 \\
\hline Instructor was responsive to questions. & 4.87 & 0.35 \\
\hline Overall, these course meetings were effective. & 4.73 & 0.46 \\
\hline Course content will be useful to me in the future. & 4.67 & 0.82 \\
\hline Course content will be useful to me. & 4.47 & 0.64 \\
\hline Course time was appropriate. & 4.47 & 0.52 \\
\hline Course content was clearly presented. & 4.40 & 0.51 \\
\hline Course materials were helpful. & 4.33 & 0.72 \\
\hline Course meetings stimulated my interest. & 4.20 & 0.94 \\
\hline
\end{tabular}




\section{F. Closing Discussion}

This study described the design of a novel three-course sequence called the Engineering-Science Intellectual Property Project (the ESIP-Project). The primary objective of the ESIP-Project is to couple IP knowledge with the engineering design process to bolster students' knowledge of IP concepts and innovative potential. While most engineering, science, and technology departments do an excellent job of teaching STEM concepts, and a much smaller percentage teach rudimentary IP concepts $[17,18]$, these two approaches are mostly left for the students to integrate. The self-integration task is not only unlikely because of the difficulty associated with such an integration, but extremely time-sensitive, as the students will quickly forget about IP concepts once they leave academia. The ESIP-Project, however, shepherds this integration and helps students internalize IP directly into their standard design approaches. Furthermore, as with anything, repetition (i.e., practice) helps. Through the three-course sequence, concepts are introduced and reinforced as the courses become progressively more complex. The three-course sequence allows ample time for the principles of IP to be internalized in student approaches, which in turn will bolster their pathways towards innovation. In sum, the programs and articles discussed herein by others fail to connect innovation and methodology of innovation for generating protectable and non-infringing IP. That is where the ESIP-Project provides its maximum impact: teaching students how to transform an innovative idea into a protectible invention that is less likely to infringe, and to do so with high quality and quickly.

In addition, in a unique fashion at the institution of the authors of this paper, students from engineering, science, and technology are mixed with law students who advise clients in the Entrepreneurship Clinic. This mixture of law and STEM students generates a fertile ground for learning as the law students bring public policy and other legal perspectives into the mix, while STEM students expound on the technical challenges. Collaboration between these two sets of students are particularly useful during the examination phase of the patent applications for both the ESIP-Project as well as the Law School Clinic. Through several semesters of legal writing, law students excel at forming legal arguments and writing legal documents, while STEM students excel in technical areas and can form arguments based on technical merits. This interdisciplinary combination of legal and technical know-how can generate a unique strength for IUPUI students. This sentiment is best captured via the Interactivity scale, which mostly provided favorable evidence regarding student-to-student support. However, one item on this post-survey, indicated that one discernable area for the ESIP-project improvement is in helping students better facilitate the knowledge of their peers. Cross-disciplinary considerations, particularly those that may have inhibited this response, will be explored in the future.

We anticipate that participation in the ESIP-Project will help students immensely in their day-today technical tasks once they graduate, as they will know how to organize their arguments in an effective and persuasive manner. During the current semester, one student group who enrolled in Course 1 is currently responding to USPTO office actions for their IP design. We anticipate this rate of response to grow in subsequent iterations. Students will put their recently or concurrently acquired MPEP knowledge to good use by generating responses to those office actions. Whether hypothetical or actual office actions are generated, the quality, presentation of ideas and arguments, effectiveness of the responses are used to measure the students understanding and grasp of these complex concepts. Fila and Hess [19] reported that both successful and failure experiences like this can be critical components for bolstering students' innovative potential. 
To achieve the project aims, the ESIP-Project, including Course 1, fostered an entrepreneurship learning environment for engineering students wherein they engaged in a systematic approach to designing and innovation. In all ESIP courses, students will prepare designs in accordance with a new pedagogical approach of teaching engineering, technology, and science with IP as a starting point. The pre-post results reported herein suggest strong, positive gains in, at the least, students' self-perception of their mastery of said content. Likewise, these significant gains were coupled with significant gains in students' understanding of innovative design and careers in patent law. While the authors recognize that the scales utilized herein are not "validated," given the small sample sizes, the profound, positive changes in student responses from enrollment in just one of three IP courses is encouraging to our team.

\section{Future Work}

We hope that the ESIP-Project model, and our evaluation of the model, will provide an outline for other educators interested in promoting entrepreneurship and innovation among their students. In the future, our team will seek to triangulate the quantitative findings reported herein with additional qualitative data sources, such as post-course student written responses and student focus groups. We will also seek to ascertain to what extent participation in multiple courses impacted students beyond participation in a single course. Lastly, we will pursue strategies for diversifying participants, such as greater representation of female students.

At the time of this writing, the ESIP-Project is in the final stages of securing a grant that will support prototype development. Specifically, local companies will work with student groups on company projects. Each student group will design solutions corresponding with a project in association with the company's engineering department. After the design is completed, each student group will create a proof-of-concept prototype, and thereafter prepare a patent application in association with the company's legal department, providing a rich engineering and legal learning environment as well as potential internship and permanent employment opportunities. The experience that students will gain through this approach will solidify concepts they learn in the classroom.

\section{Acknowledgments}

This project was supported by seed funding from SEIRI at IUPUI. We would also like to thank the students who participated in the course and survey design described herein.

\section{References}

[1] B. Obama, "Remarks by the President at White House science fair," ed. Washington, DC: Office of the Press Secretary, 2015.

[2] U.S. Constitution, Art. I, Sec. 8, Clause 8.

[3] M. V. Hernandez, "First U.S. patent issued today in 1790," ed: United States Patent and Trademark Office, 2001. 
[4] C. A. Nard and A. P. Morriss, "Constitutionalizing patents: From Venice to Philadelphia," Review of Law \& Economics, vol. 2, no. 2, pp. 223-321, 2006.

[5] Bilski v. Kappos, Supreme Court of the United States 561 U.S. 593, 2010.

[6] Apple Inc. V. Samsung Electronics Co., Ltd, 786 F.3d 983, Fed. Cir. 2015.

[7] A. L. Callahan, P. E. Givens, and H. A. Montefusco, "Current issues in manufacturing management: Intellectual Property issues in a global environment," presented at the ASEE Annual Conference, Washington, District of Columbia, 1996.

[8] K. M. Kaplan and L. C. J. J. Kaplan, "Using Intellectual Property to enhance engineering education," presented at the ASEE Annual Conference \& Exposition, Portland, OR, 2005.

[9] A. Vairis and M. Petousis, "Intellectual property teaching as part of an engineering degree," in Engineering Leaders Conference, 2014: QScience Proceedings.

[10] J. Lave and E. Wenger, Situated learning: Legitimate peripheral participation. Cambridge university press, 1991.

[11] United States Patent and Trademark Office. (2017). Registration exam results and statistics: Exam results by fiscal year. Available: https://www.uspto.gov/learning-andresources/patent-and-trademark-practitioners/registration-exam-results-and-statistics

[12] R. F. DeVellis, Scale development: Theory and applications. Los Angeles, CA: SAGE Publications, Inc., 2011.

[13] S. S. Shapiro and M. B. Wilk, "An analysis of variance test for normality (complete samples)," Biometrika, vol. 52, no. 3, pp. 591-611, 1965.

[14] J. Cohen, Statistical power analysis for the behavioral sciences. Hillsdale, NJ: Lawrence Erlbaum Associates, 1988.

[15] J. L. Hess, L. Kisselburgh, C. B. Zoltowski, and A. O. Brightman, "The development of ethical reasoning: A comparison of online versus hybrid delivery modes of ethics instruction," presented at the American Society for Engineering Education, New Orelans, LA, 2016.

[16] T. A. Brush and J. W. Saye, "A summary of research exploring hard and soft scaffolding for teachers and students using a multimedia supported learning environment," Journal of Interactive Online Learning, vol. 1, no. 2, pp. 1-12, 2002.

[17] The Center for Legal Studies. (2018). California State University Monterey Bay: Intellectual Property Law for Engineers. Available: https://www.legalstudies.com/product/california-state-university-monterey-bayintellectual-property-law-for-engineers/

[18] University of Washington - Paul G. Allen School of Computer Science \& Engineering. (2018). CSE490T: Intellectual Property Law for Engineers. Available: https://www.legalstudies.com/syllabus/intellectual-property-law-for-engineers-online/

[19] N. D. Fila and J. L. Hess, "Critical incidents in engineering students' development of more comprehensive ways of experiencing innovation," presented at the ASEE Annual Conference \& Exposition, Salt Lake City, UT, 2018. 